\title{
Extraluminal migration of a coin in the oesophagus of a child misdiagnosed as asthma
}

\author{
R A P Persaud, N Sudhakaran, C C Ong, D A Bowdler, E Dykes
}

\begin{abstract}
Ingestion of a foreign body, the commonest being a coin, is a common problem in children. In most cases the coin will pass uneventfully through the gastrointestinal tract. However, on rare occasions it may become lodged in the oesophagus with subsequent extraluminal migration with the potential for serious complications such as vascular fistula or chronic suppurative infection. A case is presented of extraluminal migration of a coin in the oesophageal associated with abscess formation in a 15 month old boy. This case is particularly important because the presenting symptom of wheezing led to the erroneous diagnosis of asthma, which resulted in a three month delay in investigation and treatment. In addition, it raises the issue of whether to perform chest radiography on newly diagnosed asthmatic patients to rule out the presence of a foreign body and thereby prevent serious complications.

(Emerg Med f 2001;18:312-313)
\end{abstract}

Keywords: coin; extraluminal migration

\section{Case report}

Approximately three months before admission to University Hospital Lewisham, a 15 month old boy was taken to his general practitioner when he started to wheeze and was diagnosed as having asthma. He did not have any other symptoms such as difficulty in swallowing his feeds or weight loss. He was treated with salbutamol and becotide inhalers but these failed to relieve his symptoms over a three month period. He subsequently developed a cough followed by a cyanotic episode and was taken to the local accident and emergency department where a diagnosis of croup was made. His symptoms improved slightly after two nebulis-

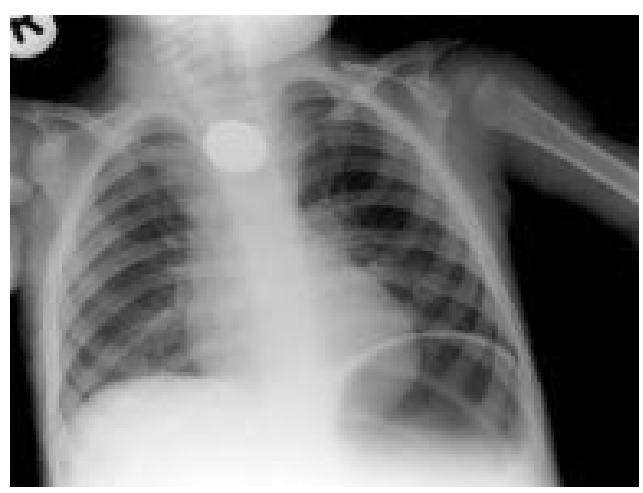

Figure $1 P A$ chest radiograph demonstrating the penny lodged in the upper mediastium. ers of Pulmicort Respules and he was discharged with a referral to the outpatient paediatic clinic. The following day he was taken back to the same hospital because of wheezy breathlessness. On this occasion a chest radiograph revealed the presence of a coin in the region of the upper mediastinum (fig 1). $\mathrm{He}$ was transferred immediately to University Hospital Lewisham for further management.

On rigid oesophagoscopy, an abnormal mass was identified in the anterior oesophageal wall but no coin was seen. Bronchoscopy showed the mass distorting the posterior tracheal wall in the region of the upper mediastium. The coin had migrated through the wall of the oesophagus and was lying in an abscess cavity betweeen the trachea and the oesophagus. An urgent lateral thoracotomy was performed and a one penny coin was retreived. Seven days later a contrast study revealed a persistent oesophageal leak. He was kept nil by mouth for two weeks and a repeat contrast swallow showed complete resolution of the oesophageal leak. He remains well on full oral diet one year later.

\section{Discussion}

Foreign body ingestion or inhalation associated with acute symptoms such as coughing, cyanosis, dysphagia or dysnoea usually leads to prompt investigation and treatment if it is brought to the attention of the medical profession. However, when the event is not witnessed, or when these symptoms are absent, it is difficult to make a diagnosis of a foreign body in the aerodigestive tract without a high index of suspicion. In our case, no one had observed the ingestion of a coin and the clinical manifestation of the foreign body was wheezing. As in children wheezing is commonly linked to asthma it is not surprising that a diagnosis of asthma was made. However, this case emphasises the need to keep an open mind when diagnosing a child with a wheeze and raises the issue of whether to perform chest radiography on newly diagnosed asthmatic children in order to exclude the presence of a foreign body.

Ingested foreign bodies usually pass through the alimentary canal without any complications, but occasionally they may become lodged in the lumen of the oesophagus. The object commonly becomes impacted in the cervical oesophagus just below the cricopharyngeus. ${ }^{12}$ Only a small proportion of these foreign bodies perforate the oesophagus and even fewer migrate extraluminally. ${ }^{3}$ Blunt objects, such as coins, may cause perforation of the oesophagus by a mechanism that involves time, pressure and foreign body reaction, 
which allows erosion of the oesophageal wall. ${ }^{4}$ Generally, the complications of penetrating foreign bodies within the oesophagus include perioesphagitis, perioesophageal abscess, vascular fistula or carotid rupture. ${ }^{6}$ To avoid such serious complications, we feel that it is important to identify and remove any arrested foreign body in the oesophagus as a matter of urgency; this is well demonstrated in the case presented.

In the nine cases reported in the English literature, of extraluminal migration of coins in children that required surgical interventions, ${ }^{3-5} 7$ only two postoperative complications were documented. The first patient had a previously repaired congenital tracheo-oesophageal fistula and his ingested coin was lodged at the site of the repair and had eroded partly into the right bronchus and partly into the mediastinal tissue; postoperatively the fistula re-opened but closed spontaneously within four weeks. ${ }^{4}$ The other postoperative complication was a small posterior oesophageal fistula, which closed after two weeks of conservative management. ${ }^{7}$ In our case there was a small postoperative leak that meant that the child was not able to resume oral feeds for a few weeks.

In conclusion, this case illustrates clearly that not every child with a wheeze has asthma.
In addition it may be wise to perform chest radiography on newly diagnosed asthmatics, especially those not responding to first line anti-asthma medications.

Contributors

Ricardo Persaud reviewed the literature and wrote the paper. Nada Sudhakaran assisted at the thoracotomy operation and contributed to the literature search and illustration. Chun Ong admitted the patient, assisted at the endoscopy and contributed to the discussion of the core ideas. David Bowdler initiated the idea to write up this case report and was the consultant responidea to write un this case report and was the consultant responsible for the patient at the initial consultation. He performed the initial endoscopy and also edited the first draft. He was responsible for the overall supervision. Evelyn Dykes performed the thoracotomy and was the consultant responsible for the postoperative care and outpatient follow up. She also contributed to the writing of the draft and final versions of the paper. Ricardo Persaud is the guarantor.

Funding: none.

Conflicts of interest: none.

1 Nandi P, Ong GB. Foreign body in the oesophagus: review of 2,394 cases. Br F Sur 1978;65:5-9.

2 Obiako MN. Tracheosophageal fistula; a complication of a foreign body. Ann Otol Rhinol Laryngol 1982;91:325-7.

3 Remsen K, Lawson W, Biller HF, et al. Unusual presentations of penetrating foreign bodies of the upper aerodigestive tract. Ann Otol Rhinol Laryngol 1983;92:32-44.

4 Yee KF, Schild JA, Hollinger PH. Extraluminal foreign bodies (coins) in the food and air passages. Ann Otol 1975;84: 619-23.

5 Janik JS, Bailey WC, Burrington JD. Occult coin perforation of the oesophagus. F Ped Surg 1986;21:794-7.

6 Burton DM, Stith JA. Extraluminal esophageal coin erosion in children. case report and review. Int F Ped Otorhinolaryngol 1991;23:187-94

7 Nahman BJ, Mueller CF. Asymptomatic esophageal perforation by a coin in a child. Ann Emerg Med 1984;13:627-9. 